\title{
Integrated use of Treetop Solar as an Essential Part of Outdoor Landscaping
}

\author{
Shubham A. Surana
}

\begin{abstract}
In today's climate of growing energy needs and increasing environmental concern, alternatives to the use of non-renewable and polluting fossil fuels have to be investigated. One such alternative is solar energy. Much of the world's required energy can be supplied directly by solar power. More still can be provided indirectly. The practicality of doing so will be examined, as well as the benefits and drawbacks. In addition, the uses solar energy is currently applied to will be noted. Conceptually, Solar treehouses are not referred to as an essential component for outdoor domestic landscaping. This study makes it a point to make the readers fully aware of the design of such structure and its beneficiaries, carrying along a study of its multipurpose use and its advantages and disadvantages.
\end{abstract}

Keywords: Solar TreeTop Landcape mltipurpose benefits aesthetic conventional

\section{Introduction}

A huge Impact has been seen, since TreeHouses in Rochester and Maine situated in the U.S. have been an eye-catching site for the tourists as well as the localites, on the Outdoor Aesthetics of a property or be it their conventional benefits for disciplinary use of space. It contains a multi-purpose outlook and is also easy to maintain and build component. In India such conventional rehouses can be rarely found in area like Himachal, Mahabaleshwar, Jaipur and Bandhavgarh where its only used for resorts and cottages. Domestic use of such aesthetic is barred due to negligence towards its leverages.

Solar is not just a very widely famed technology today, but according to the state of cities climatic condition in the Deccan plateau region it has become a necessity to harness the otherwise wasted bit of hate received.

Following the apprehensive methods use in the United States region western-Europe study states treetop structural decorative or treehouse engineering to be a common component in the outdoor landscape architecture.

They are supposedly used for different purpose as for leisure aesthetics out- house and many more. While planning an outdoor landscape it mandatorily suggestive as to which trees to be planed around considering climatic soil geological, and aesthetical need of the structure such trees are grow.

Effective method, used cumulatively can solve the use for self- generation of electricity for the treetop structure as well as the entire outdoor landscape for that matter.

The International Energy Agency as stated in its journal how it figure on to make solar photovoltaic's \& focused solar power contribute to 16 to $11 \%$ of worlds electrical energy production.

In addition to the tree design concept of solar treehouse the research also highlights numerical benefits on a city area basis a study of earlier use technique in a house olds is attached with some statistics of a model city followed. A two- dimensional graph \& calculation approach leading to conventional beneficiaries is what take achieve. The practical usage is a broadly supportive to the theoretical presenting of energy production methods.

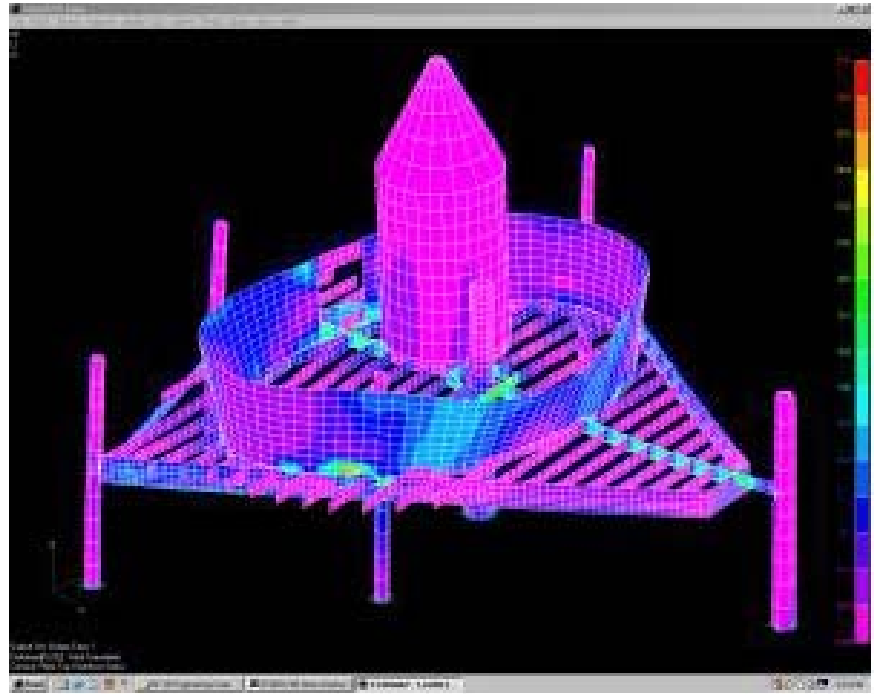

Bangalore: Romance on a tree top! lif you want to spend your romantic trip on nature's lap then tree house resorts are the ultimate options. The regular tourist destinations for couples could get outdated and boring, but romantic tree houses are a must visitl It lets you have a chance to be closer with nature and enjoy in the serene atmosphere away from the rest of the world. These outstanding tree-top houses ofer thrill and adventure at its best, which can make your romance ablaze. Below is the list of such unique tree house resorts in India.

\section{1) Vythiri Resort}

Located in: Kerala

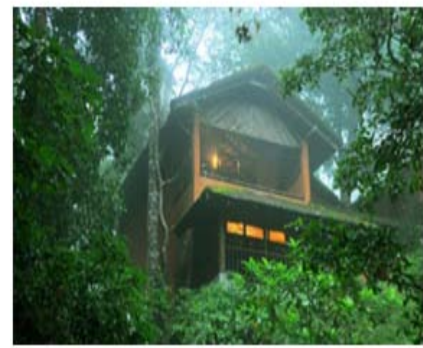

All five luxurious tree houses at Wythiri Resort are located 70 feet up in the lush green rainforests of Wayanad, Kerala. This romantic tree-top gateway can be accessed by two ways, one by wooden steps and another by a crane lift. It offers outstanding living experience overlooking the pristine jungle. During the stay, you can also enjoy some exciting activities including rainforest treks, bird watching, trips to close by spice plantation and jungle expedition. Besides, Wythiri Resort tree-houses are the winner of the International Quality Crown Award. The eco-friendly surrounding of this place makes an ideal option for romance, relaxation and rejuvenation. 


\section{International Journal of Science and Research (IJSR) \\ ISSN (Online): 2319-7064 \\ Index Copernicus Value (2013): 6.14 | Impact Factor (2015): 6.391}

2) The Machan

Located in: Maharashtra

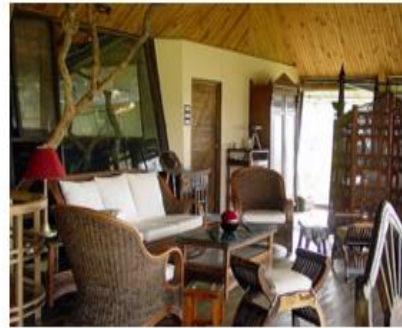

If you are seeking isolated gateway in India, The Machan' is the perfect tree house destination. Nestled 45 feet up on wild fig trees in the jungle, the resort offers panoramic view of the valley below. Hidden in the middle of dense forest of Jambulne in the Sahyadri Hills of the Western Ghats, the treehouse resort is an eco-friendly jungle retreat. This four-level tree house includes a main deck, hanging room, loft and crow's nest and each level can be accessed by a spiral staircase. The resort has wind turbines and photovoltaic cells by which they

produce their own power. This tree-house includes large space that can accommodate six people at a time.

The Machan is close to Lonavala, one of Maharashtra's famous tourist gateways and about two and a half hours drive from Mumbai. The most exciting feature is the five kilometers of private walking tracks to explore the pristine jungle.
6) Tree House Resort

Located in: Jaipur

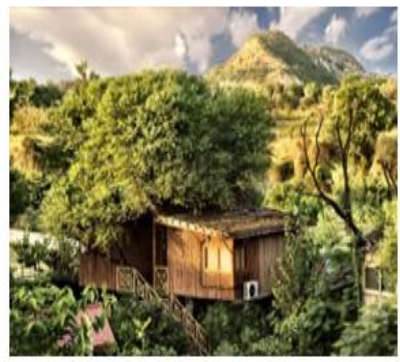

Tree House Resort is located at Nature Farms in the Syari Valley, which is only a 30 minutes drive from the pink city, Jaipur. It offers luxurious tree houses with every comfort of its kind and the panoramic view of the Aravallis. Built atop strong on Keekar trees 'Tree House Resort' are the only natural resort in Rajasthan. The primary theme of this resort is to bring people back to nature, but with the same trappings of an urban existence. It provides the entire range of necessary facilities one needs like, airconditions, TV, comfortable mattresses and furniture.

\section{Design Procedure of Treehouse Solar}

Here is a system of Anchor Fasteners and Girders, that shall be used thoroughly around the globe is the most tree \& load friendly support device available

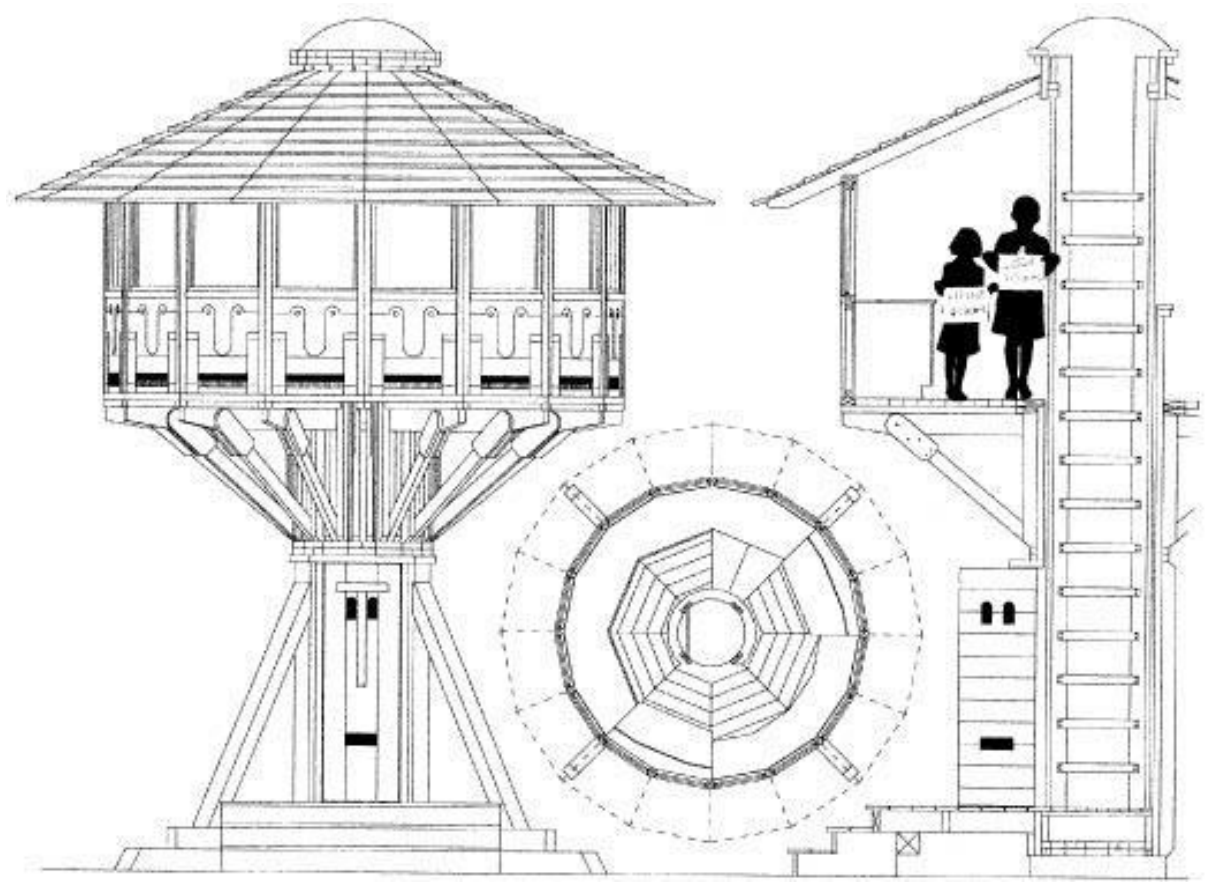

Fasteners come in configuration as:

\begin{tabular}{|c|c|c|}
\hline Large Trees & Medium Trees & Small trees \\
\hline $750 \mathrm{~cm}$ or $20 "$ dia. & 30-50 cm or dia. $12 "-$ & $22-26$ \\
\hline Most load supported & 20" supported beams on & 9"to14" dia. \\
\hline$\&$ can be mounted as & each side and \& keep & specifically \\
\hline $\begin{array}{c}\text { a cantilever holds } \\
\text { beams }>5000 \mathrm{~kg}\end{array}$ & $\begin{array}{l}\text { load down the center } \\
\text { line } 79500 \mathrm{~kg}\end{array}$ & \\
\hline
\end{tabular}

Engineering /Design service are billed Provides actual load testing, periodic re-torque, lowest amount of tree tissue removal \& cost for true load Supported.

For a case where a tree house or structural component on a tree is build as a image shows bellow \& there is an arbitrary need for a rooftop solar to be fitted the following steps are followed.

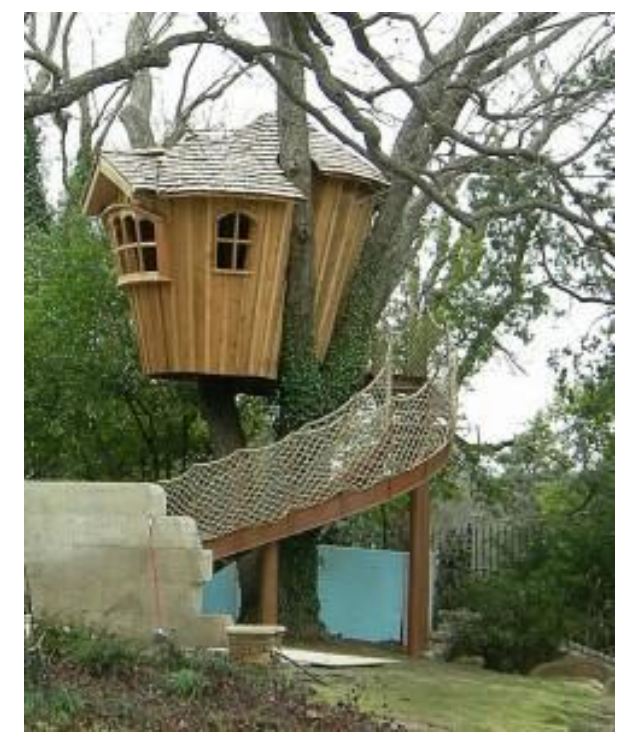




\section{International Journal of Science and Research (IJSR) \\ ISSN (Online): 2319-7064 \\ Index Copernicus Value (2013): 6.14 | Impact Factor (2015): 6.391}

1) A site visit to the treehouse \& hence followed by its complete analysis.

2) Site arrestment Analyze the treetop or treehouse roof as with the help of google earth determine adequate sun exposure for energy rebate.

3) Once determined the above criteria measurement of the roof \& help decide what size and area covering with which light capacity solar panels aptly suitable for the structure.

Types of Solar Panels

- Monocrystalline Silicon (Single Silicon)

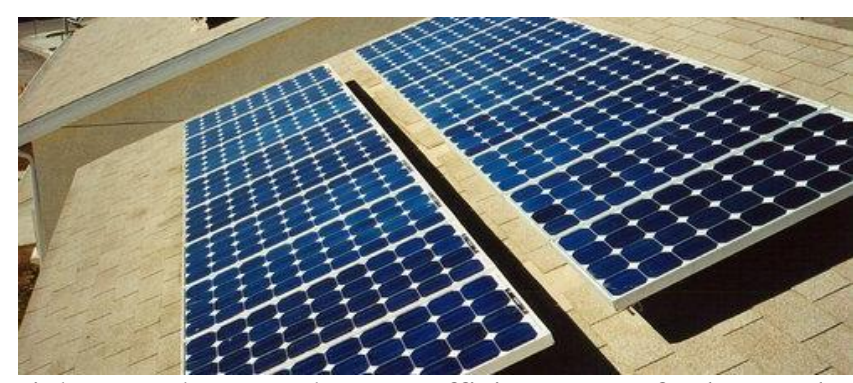

Right now, these are the most efficient types of solar panels

- Polycrystalline Silicon (Multi-silicon)

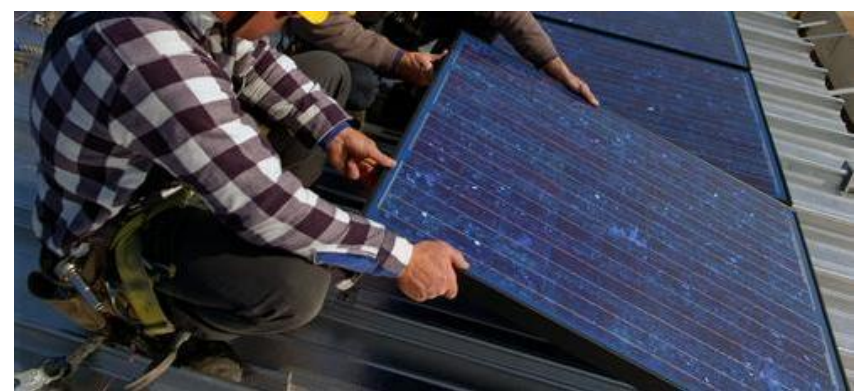

Everyone talks about "thin film" because they're really inexpensive to make and they don't mind the heat, which is all cool. Except right now, they're very inefficient, which means you'll see them in big solar farm projects with a lot of land, but not on your roof.

- BIPV (Building Integrated Photovoltaics)

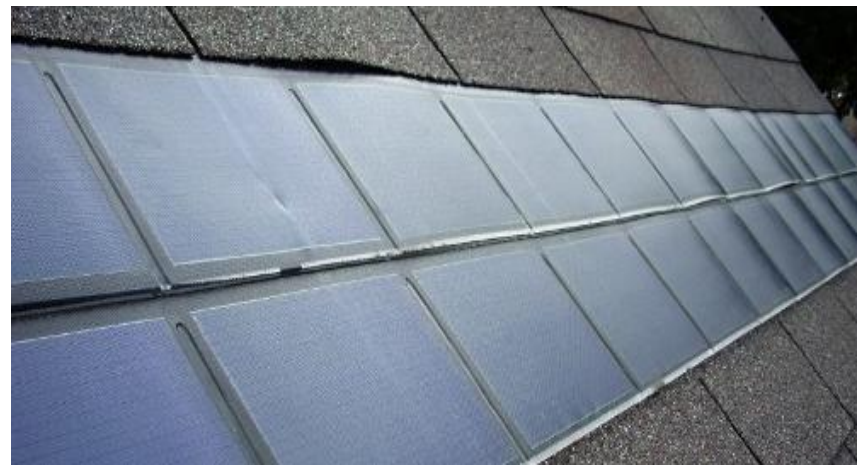

BIPV's can look like real roofing tiles (solar shingles are an example). That's nice, but good looks do cost a lot more.

1. Optional Banking and financing if not on spot affordable package of treetop solar available generating subsidy for electricity generated \& a reward facility for conventional method using.

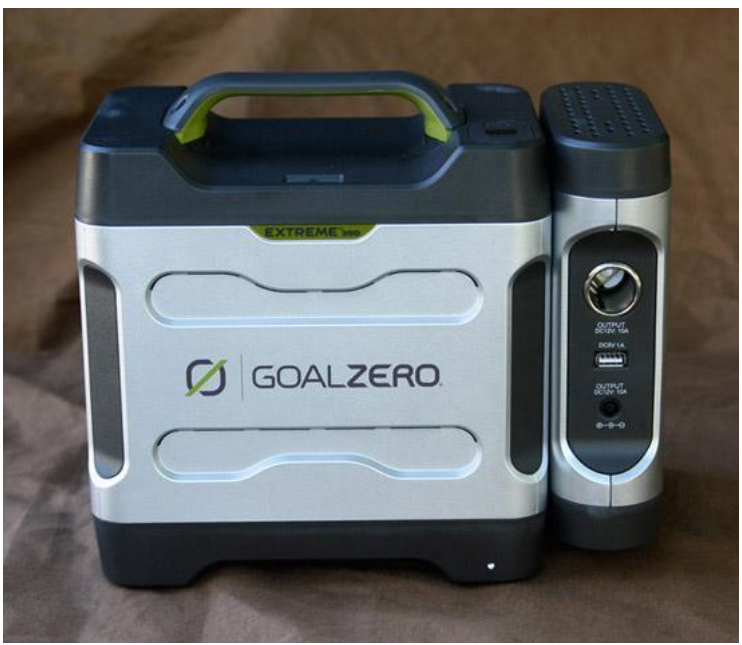

This makes idea of solar Treehouse attainable

- Built below trees center of gravity

- If possible let 2-3 trees share the load

- Use basic tools, hardware to puncture trees so they don't destroy the nutritional value and its core strength.

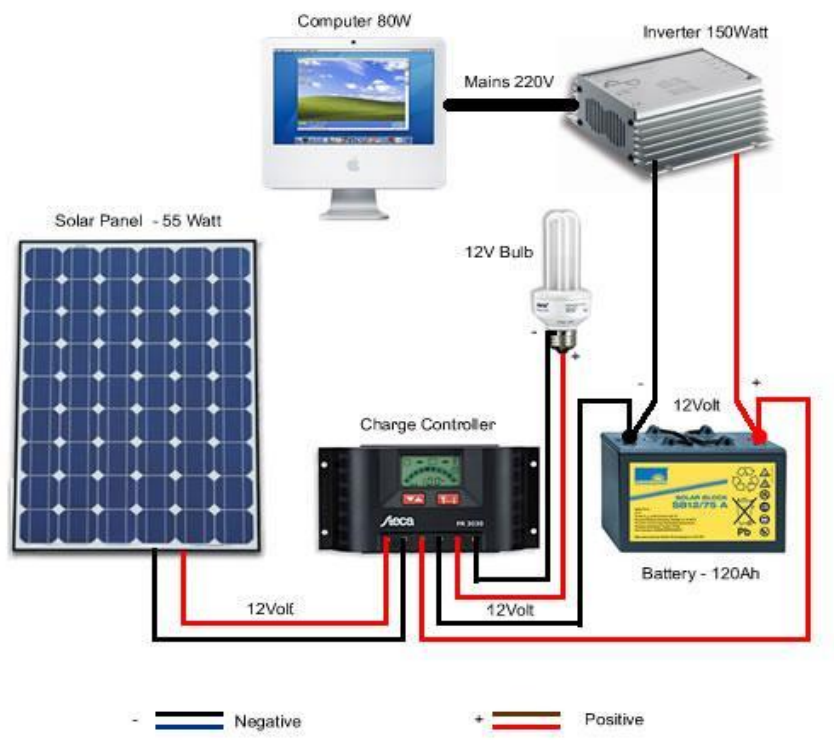

Case Study for the Benefits of Pune City (Maharashtra, India) 


\section{International Journal of Science and Research (IJSR) \\ ISSN (Online): 2319-7064}

Index Copernicus Value (2013): 6.14 | Impact Factor (2015): 6.391

\section{Reduction in Tree Growth}

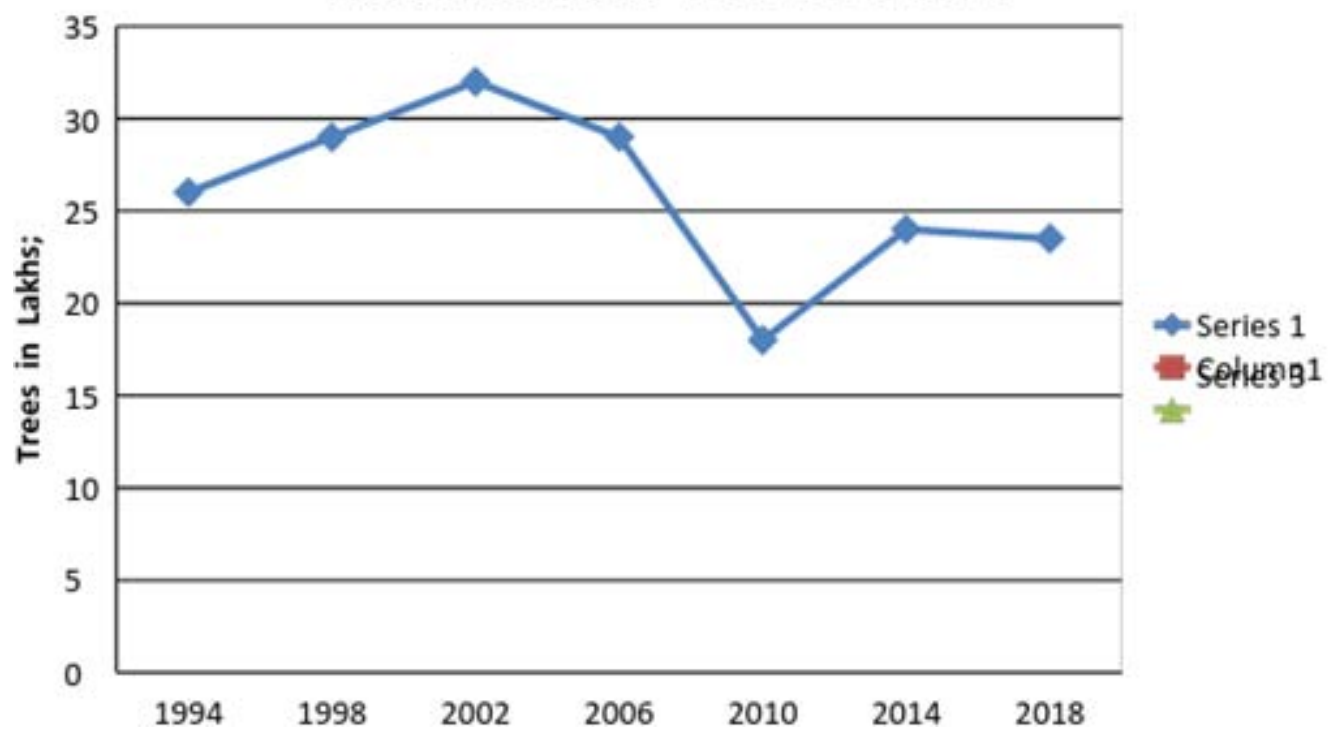

Hardly observe in any areas in and around Pune not even 3\% of the trees planted or existing are used for and conventional energy generating or regenerating purpose.

Closely the same is the case all over India where trees are not use for harnessing solar power at all where they are cut highest grasping agents of head from the sun.
A treetop can hold solar panel i.e. 20,00,000 solar panels of area $30,00,00$ sq.ft. i.e. a system of 5,80,000 kw i.e. $580 \mathrm{MW}$ : i.e. 2,11,700 MW-hr/year. Saves Rs. 19,53,00,000/year

According to the calculation of energy economics it is enough suffice needs of 1074institution all buildings electricity need saving up to $\underline{30,00,000}$ sq. ft. area of Pune city.

According to the study relevant to the graphs above if treetop solar are installed on the no. of trees i.e. 24.26 lakh in Pune.

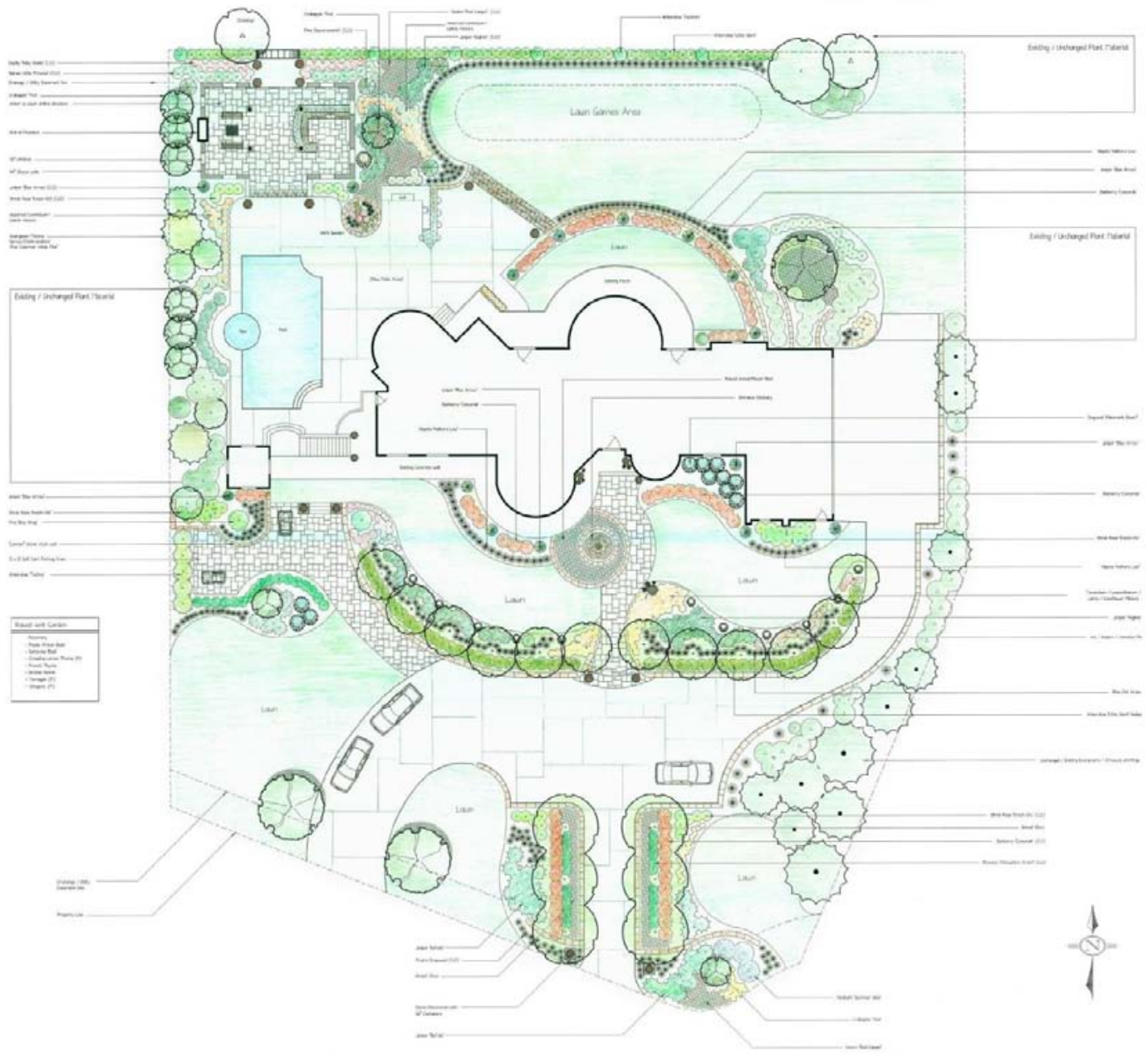




\section{Advantages of Solar Treetops}

1) A must and a need of environment.

2) Focuses on reduction of wastage of space that can be else used.

3) A very conventional stated methodology as for promotion of solar.

4) Associated with the long term benefits as has broad perspective of achieving energy goal as a substitute to outer harmful production method of electricity.

5) Saving of huge amounts of money possible on a yearly basis.

6) Less of maintenance required.

7) Can even make use of soltened trees acquiring space in forest/hilly areas.

8) Beneficial in all sizes as per the size or the requirement of the vicinity.

9) Planned efforts can result in proper structural arrangements and safe energy harnessing at low cost investment of saving innumerous space.

10) Solar Power Tree House Provide independence.

\section{Disadvantages of Solar Treetops}

1) Easily combustible in accidental cases.

2) Needs a thorough investigation of the areas as to pass its criteria of so we live wires passing bye.

3) Need good structural strata with hefty tree branches.

4) Initial investment is huge amount but surely reaps timely *ROI and benefits.

5) Non-functional during gloomy month of the year.

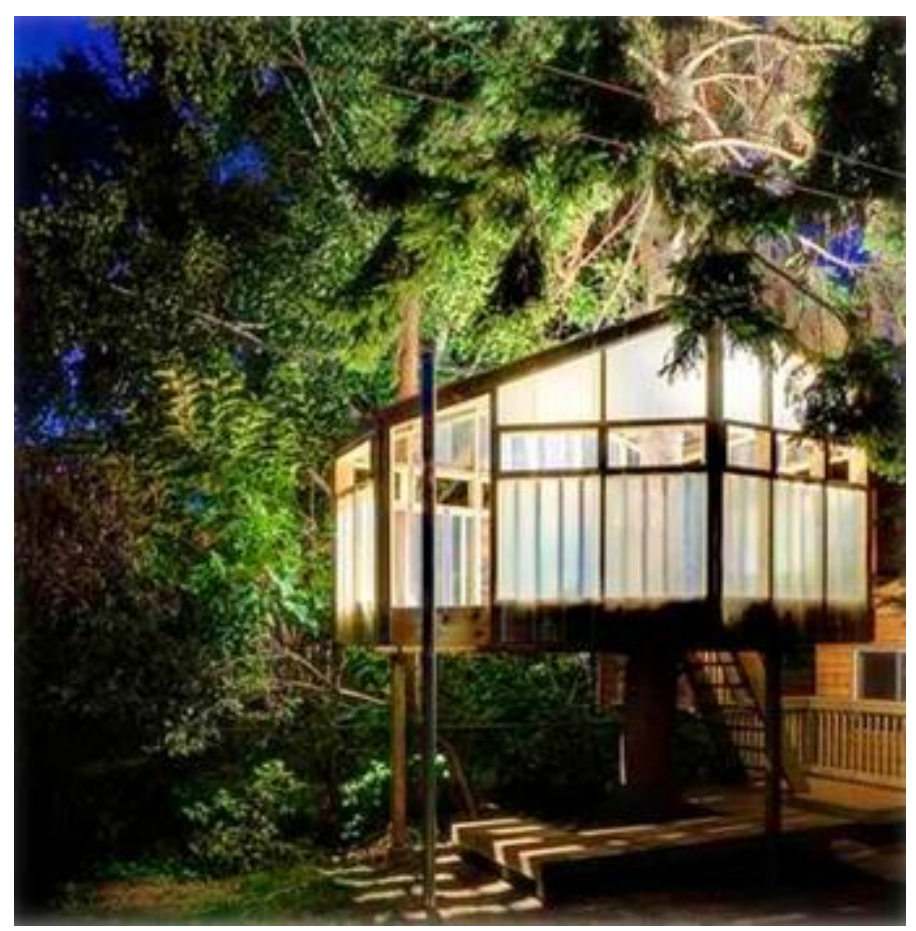

